\title{
Frequency distributions of storm surge for coastal damage prevention at Marseilles
}

\author{
P. Gaufrès ${ }^{1,2}$ \& F. Sabatier ${ }^{2,3}$ \\ ${ }^{1}$ Centre d'Etudes Techniques Maritimes, CETMEF, France \\ ${ }^{2}$ Centre Européen de Recherche et d'Enseignement en Géosciences de \\ l'Environnement, CEREGE, France \\ ${ }^{3}$ Faculty of Civil Engineering and Geosciences, \\ Delft University of Technology, The Netherlands
}

\begin{abstract}
Densely low-lying populated areas and sand beaches along the Mediterranean French coast are threatened by extreme sea levels. In micro-tidal conditions, the long term hourly water level record available at Marseilles Endoume (1885-2003) has made possible statistical analysis usually computed on continental hydrological parameters. Frequential analysis tools, applied to time series near to the million data, are implemented in order to provide a calculation method for the stochastic meteorological storm surge component to characterize coastal inundation and erosion risk. Surge probability distributions tested with an associated confidence interval (GEV, Jenkinson, Gamma, ...) and extreme values of the data fitting (Maximum Annual and Peaks-Over-Threshold) are discussed with relative tests (stationarity, independence, homogeneity,...). Surge stochastic results are compared with sea-levels of morphological significance correlated to coastal impact observations during storm events. The statistic methods and tools presented contribute to a better knowledge of intensity, frequency and duration of extreme sea levels associated with morphogenic storms and provide guidelines for coastal risk mitigation.
\end{abstract}

Keywords: extreme values, probability distribution, GEV, POT models, Bootstrap, surge, sea-level, coastal risk, Rhône delta. 


\section{Introduction}

The shoreline moves permanently under the combined action of sea, wind and inland waters, which results in alongshore alternation of projection or retreat. The retreat trend on the Camargue coast observed during the twentieth century forced the state administrators, coastal managers and scientific community to study actively the morphological evolution of the delta and meteo-marine agents forcing these processes (Sabatier and Suaniez [1]). Characterization of coastal risks requires a fine knowledge of sea level variations and their consequences on hydro-sedimentary dynamics on the shoreface.

The risks prevention plans (PPR) are the privileged tool of prevention policy and major natural hazards control carried out by the French State. These plans, under development on the mediterranean coast, are designed to make the risks known for the regional planning and the management of the coastal zones. On the national level, the frequential analysis of the extreme surge was carried out by the SHOM (Service Hydrographique et Océanographique de la Marine) on the Atlantic and English Channel coasts by Simon [2] starting from a statistical study of the marine levels, mainly for navigation needs. More recently, following the storms of December 1999 and the flooding of the nuclear power station of Blayais (Gironde), EDF (Electricité de France) was led to recalculate the conditions of altimeter setting of the platforms of the nuclear power stations. Pirazzoli [3] studied the recent variations of the weather factors on the Atlantic coast of France. No exhaustive and comparative study of the coastal maregraphic data has been carried out to this date for the French Mediterranean sea.

The increasing demographic and tourist pressure on the coasts force one to provide a quantified answer on the Rhône delta coast in particular, where river flood and storm surge can be concomitant. The conditions of the morphological answer (speed retreat of the shoreline, frequency of immersion...) are still not well known, in particular those concerning thresholds of fragility of the coastal systems. The vulnerability of the coastal zones and the ecosystems must be correlated to the frequency of meteo-marine forcings to release effects of tendency, taking into account the assumptions of climatic change projected till 2100. Thus, this study takes part in the effort of research of ORE RESYST (Regional Observatory of the Environment "Answers of a deltaic system to external forcings") and is realised within the IMPLIT program (IMPact des évènements extrêmes -tempêtes et surcôtes - liés au Changement Climatique sur les hydro-systèmes du LITtoral méditerranéen français). IMPLIT is supported through the GICC group (Gestion et Impacts du Changement Climatique) constituted by the MEDD (Ministère français de l'Ecologie et du Développement Durable).

This study settles in the continuity of the works of Bruzzi [4] on the impact of the storms on the Eastern coast of the Rhône delta, of Wöppelmann [5] on the control of the measurement of sea level in Marseilles and of Walton [6] on the statistical inference of extreme surges and behavior of upper tail of marine surge distributions. 


\section{Physical background}

The area of study, fig. 1, extends along the coastline influenced by the Rhône (Camargue) to the Cap Croisette at the end of the Gulf of Marseilles ( $45 \mathrm{~km}$ from the Grand Rhône mouth). The tide range is $0.3 \mathrm{~m}$ and sea-level rise is estimated to be $2 \mathrm{~mm} / \mathrm{yr}$.

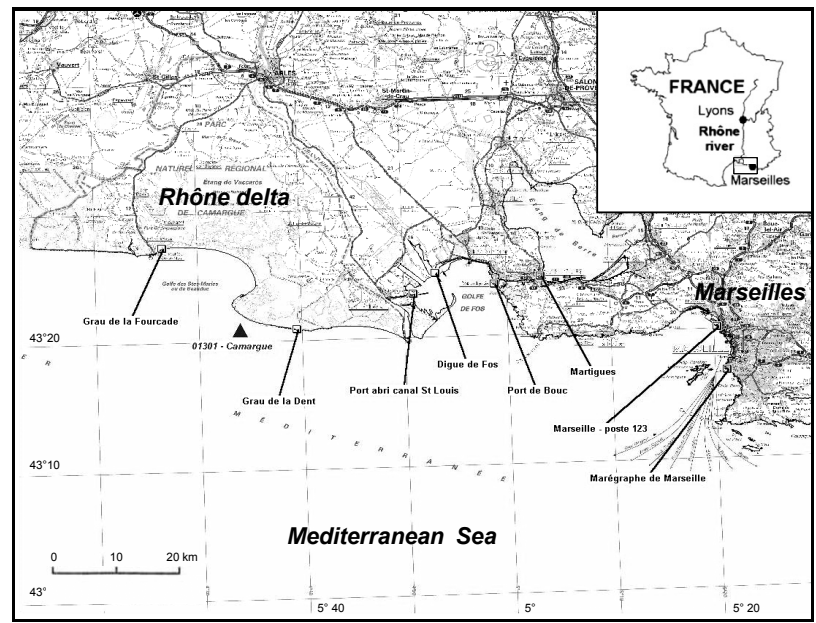

Figure 1: Area of the study and tide gauges location.

On the west side, the coast of the Rhône delta - wave-dominated according to Galloway's classification - is $90 \mathrm{~km}$ long, $85 \%$ of which are coastal protection equipped. The Camargue shoreline is characterized by sandy offshore bars bordering salt marsh zones and forms the deltaic margin. Due to the reduction of sediment supply as a consequence of dam building and evolution of the vegetation of the catchment area, the sedimentary building is more fragile to storm impacts (Vella and Provansal [7]). Shoreline displacements can reach 10 $\mathrm{m} / \mathrm{yr}$ locally. Camargue island is subjected to the concomitance of flood hazards and marine inundations. Alluvial valley can be influenced by sea levels as far as $50 \mathrm{~km}$ inland.

The Eastern part is composed successively of the Gulf of Fos formed by the secular progradation of the Eastern lobes of the Rhône, then of a steep rocky coast (Estaque). Currently, the Gulf of Fos is occupied by an industrial harbour complex and accommodates an increasing maritime traffic protected by Gracieuse spit. The Gulf of Marseilles and the Bay of Prado constitute the two great sedimentary units and also urban zones with strong stake in terms of protection of people and goods. Sedimentary displacements are limited by coastal defenses. High sea levels can cuase worse coastal river flooding in the downstream parts (Huveaune, Vieux port,...). 


\section{Tide gauge records and data pretraitment}

A significant number of tide gauges were listed after investigation into the area coastal managers. Most of the data available is on paper, and unfortunately the low-lying coast of Camargue - most vulnerable with respect to the variations of sea level - has only two sites of measurement: Grau de la Fourcade (short hourly set available) and Grau de la Dent (daily data of salt-extraction level equipment since 1905 affected by poor quality maintenance).

Eventually, the data gauge of Marseilles in the Calvo Cove (Endoume), in operation since 1885 is retained for a statistic exploration taking into account the length of the serie, unique on the French Mediterranean coast. Marseilles Endoume is part of the network of GLOSS (Global Sea Level Observing System) of $1^{\text {st }}$ category. Initially built for the definition of the French altimetric system by the NGF Service (general levelling of France), the sea level observatory produces two series of measurements: recordings on roller paper which provide the temporal variation of the sea level and monthly averages of the sea level obtained with an exceptional mechanical adding machine. The historical equipment worked until 1988 and was replaced in 1998 by an acoustic tide gauge in the same stilling well. Hourly series (1885-2003) and predicted tide were provided by SHOM.

The control of the series of values highlighted a variable temporal shift. One notes that the meteorological residue (predicted tide deduced from sea-level data) preserves an undeniable periodic character which could be explained by signal filtering function of the geometry of the observatory (feeder canal to float chamber and water gate) or obstruction of this during years of poor maintenance. As an explanation has not yet to be found, the repercussion of this temporal shift in terms of uncertainty over extreme surge was quantified before the statistical analysis. It proves on the one hand that maximum error is lower than the centennial result variations of studied laws adjustment, and on the other hand that the variations - positive or negative - tend to be balanced for the whole of the data set (characteristics summarized in table 1).

Table 1: $\quad$ Marseilles Endoume tide gauge data characteristics.

\begin{tabular}{|l|l|}
\hline Beginning & 12 February 1885 \\
\hline End & 31 December 2003 \\
\hline Absolute length (years) & 119 \\
\hline Availability (\%) & $75,6 \%$ \\
\hline Missing data (\%) & $24,4 \%$ \\
\hline Equivalent full years available & 89,96 \\
\hline Hourly records & 911650 \\
\hline
\end{tabular}




\section{Statistical models and distribution fitting control}

Modeling theory of the hydrological extremes is particularly developed in continental field taking into account the stakes in terms of regional planning and density of measurements. Tools of statistical inference elaborated during decades adjust extreme statistical laws on the data considered as random variables (Gumbel [8], Jenkinson [9]). It classically calls upon two methods: Maximum annual (MA) analysis constitutes a traditional approach, easy to implement. On the other hand MA analysis retains only one value per year: rich information of intense years are not taken into account. POT (Peaks-Over-Threshold) method usually leads to better adjustments because it takes into account the whole information available and corresponds to a measurable physical reality on the ground (sea flooding, overflows, ...). This technique is recommended in France by IRSN (Institut de Radioprotection et de Sureté Nucléaire) for nuclear power station sites. However the choice of threshold of reference influences the quality of results (Mousavi [10]).

The bibliographical analysis provides few examples of thorough statistical assessment of storm surge distributions. A more complete description is given in meso-tidal conditions (Sandy Hook, New Jersey, US) by Walton [6]. Having a long hourly series (1935-1996), he observes that if many probability distributions can be used for the current frequencies, none can be dissociated as particularly fitting over the entire experimental data. One notes significant discrepancy in the surge magnitudes for large return periods critical to hazard prevention.

The parameter estimation of probability laws is carried out according to two methods: maximum likelihood (ML), most current, and method of moments, generally less advised, which uses relations known between the parameters of the law and the series. The goodness-of-fit, measured initially according to the traditional Chi-squared test of Pearson appears not very relevant. In the second time, the Bootstrap method is used for robustness analysis.

\subsection{Maximum annual analysis}

The results of MA adjustments are computed with SAFARHY software developed by Institut de Recherche et Développement (IRD). From the available data set (1885-2003), 15 years of completely missing data were excluded. No additional criterion of exclusion of incomplete years was retained. As a matter of fact, application of $80 \%$ availability for a year and/or main surge season (November to February) leads to draw aside four of ten greater observations.

For the ML estimation parameters method, Gumbel adjustment is relevant for $\mathrm{T}<10$ years. Moreover, one notes a clear divergence, the twenty strongest surges are located below the adjustment. The two strongest events leave the confidence interval at $95 \%$. For the moment estimation parameter method, only two strongest surges move away from the adjustment and the maximum plot leaves the confidence interval at $95 \%$, fig. 2 . 
58 Safety and Security Engineering II

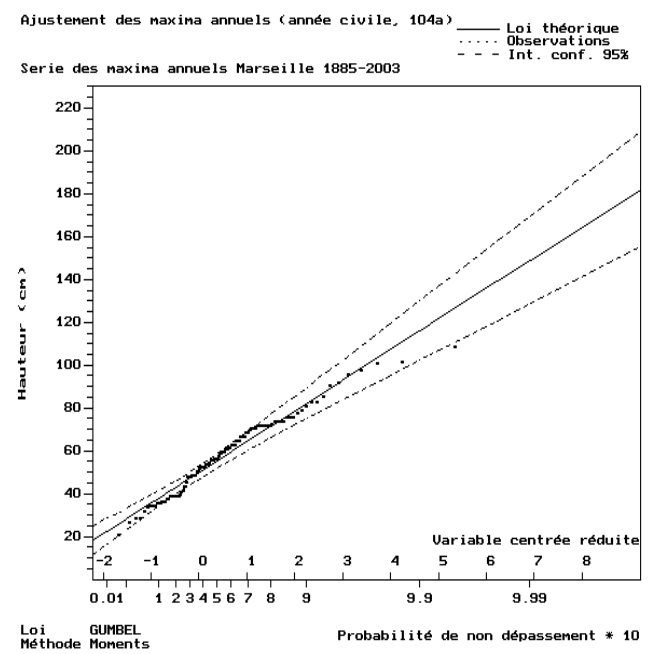

Figure 2: Gumbel EV1 distribution - moments estimation method.

Jenkinson distribution, fig. 3, proves to be equivalent to Gumbel in comparison with the Chi-squared test. However, graphically the goodness-of-fit is much better for the tail of the sample which is explained by an additional parameter. The third parameter of Jenkinson $(K=0.153)$ is significantly different from zero which confirms that the law of Gumbel $(\mathrm{K}=0)$ is not adapted to this series. Lastly $\mathrm{K}$ is positive, the MA series has a hyperexponential behavior of GEV2 type $(\mathrm{K}>0)$, characteristic also of the rains and flows in continental hydrology.

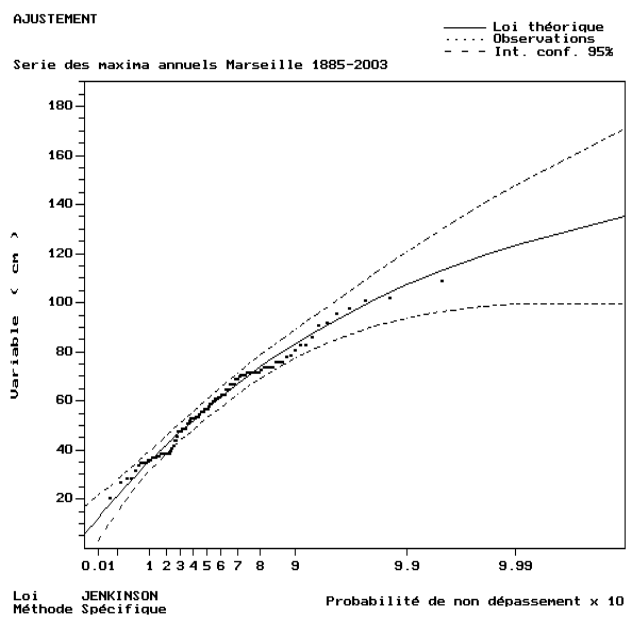

Figure 3: Jenkinson distribution (3 parameters). 
Synthesis of adjustments confirms Walton [6]'s conclusions: all the usual laws tested: Square Normal (ML), Gumbel (ML and moments), Log Normal (ML), Gamma (ML), Weibull (ML), Poisson-Exponential (moments), Jenkinson (spe.) with MA method are applicable to the series of Marseilles for the current frequencies $(\mathrm{T}<50 \mathrm{yr})$. For three parameters laws, Jenkinson and Gamma guarantee a priori a better fitting for the interval $\mathrm{T}=[50 \mathrm{yr}, 100 \mathrm{yr}]$. Beyond, the confidence interval strongly widens, they are not more relevant and the GEV 2 type laws (Frechet, Pareto, Cauchy, ...) are recommended ( $\mathrm{T}>100 \mathrm{yr}$ ).

Bootstrapping the data, fig. 4, illustrates the variability of $2 p$ and $3 p$ distributions with the MA method, and makes it possible to draw the following conclusions: two parameter distributions keep all their relative position. Gumbel (ML $-2 \mathrm{p}$ ), the use of which is strongly widespread for the analysis of the extreme values, was revealed to be not very efficient (systematically overestimating for $\mathrm{T}>50 \mathrm{yr}$ ), and Weibull (ML - 2p) undervalued as well. Jenkinson (3p) which appeared to fit the best MA data for $\mathrm{T}<100 \mathrm{yr}$, also reveals the strongest sensitivity to the resampling (multiple intersections). All laws provide the centennial quantile with a variation close to $5 \%$ (either $5 \mathrm{~cm}$ ) except Jenkinson (3p) with 7,3\% of average deviation to the original data on 20 series resampled.

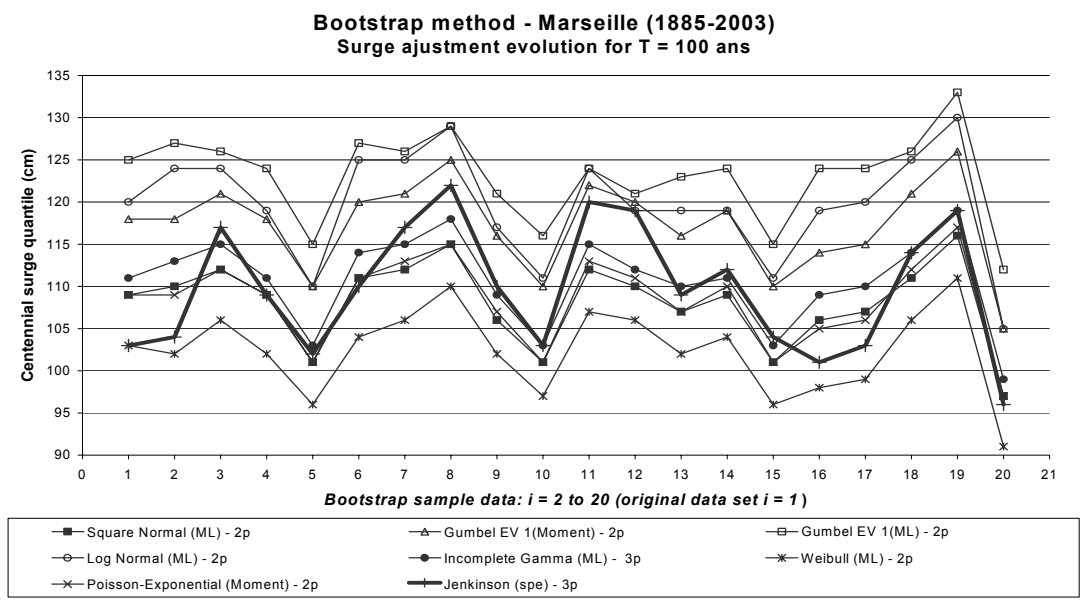

Figure 4: Bootstrap method - Robustness of maximum annual distributions ( $\mathrm{T}=100 \mathrm{yr})$.

\subsection{Peaks-Over-Threshold analysis}

Constitution of the POT series is much more complex. The choice of the parameters of sampling (threshold and independence duration of successive events) conditions the quality of the adjustments. A great attention is thus to carry to the constitution of the sample. Walton [6] had fixed the independence interval at 72 hours for the US Atlantic coast without justification. A temporal independence criterion is obtained here with 24 hours, using the autocorrelation 
test of step 1 advised by Miquel [11]. Various thresholds were then tested with methodology developed by Lang et al [12]: test of mean number of overthreshold events and test of the dispersion index. Distribution of mean number of over-threshold events per year, fig. 5, is identical to the description made by Lang et al [12]; domain $\mathrm{n}^{\circ} 2$ corresponding to decreasing threshold where statistical optimum is reached (2 to 4-6) according to Mousavi [10].

This value $(45-50 \mathrm{~cm})$ corresponds to that recognized like the geomorphological reference threshold by Bruzzi [4]. Ground observations during six storms in Camargue (1995-1998) highlight this threshold for the evolution of sedimentary stock and shoreline; the highest surge episodes also correspond to the morphogenic storms. Thus, thresholding isolates exceptional events and confirms the interest of surges as magnitude indicators of the storms, correlated with coastal impacts.

Finally, the POT method with exponential distribution provides adjustment results similar to those obtained with the MA method, the theoretical curve tending to over-estimate slightly extreme events.

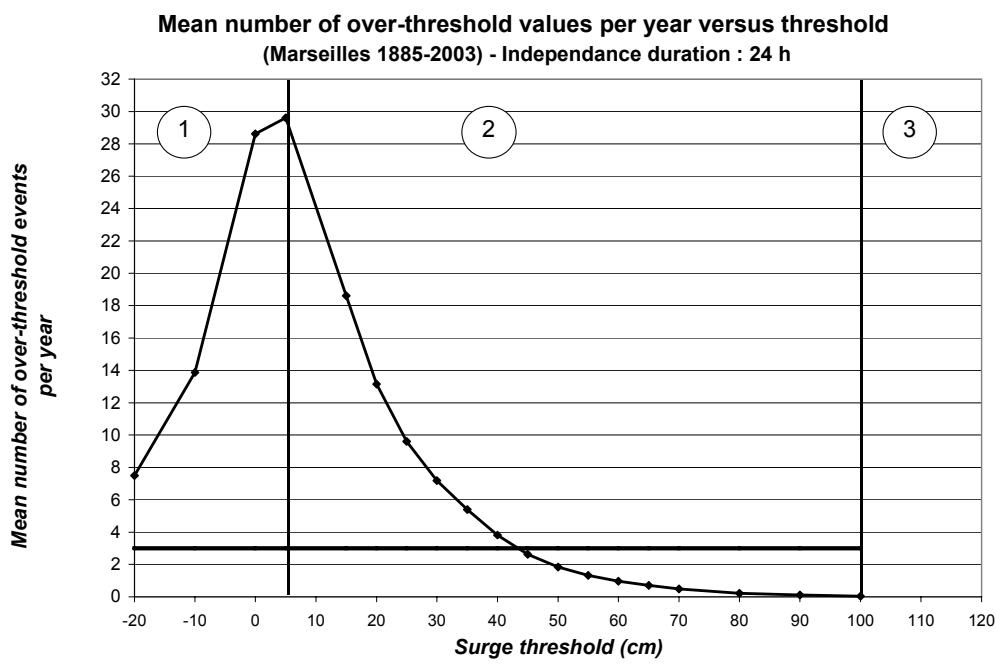

Figure 5: $\quad$ Mean number of over-threshold events per year.

\section{Intensity-Duration-Frequency curve}

In the preceding sections, storm surges are studied in intensity terms. This last part following the adjustment results proposes a synthetic statistical indicator used in continental hydrology: Intensity-Duration-Frequency curves, fig. 6. As a matter of fact, intensity is not the only parameter of physical signification; duration must be combined with magnitude to appreciate an impact event. The permanence of surge over a threshold for a long time can generate more damage than a more intense "flash" surge, taking into account the joint probability of wave occurrence (Pugh and Vassie [13]). 
Intensity-Duration-Frequency curve - Marseille (1885-2003)

Storm events with Gumbel (ML) ajustement

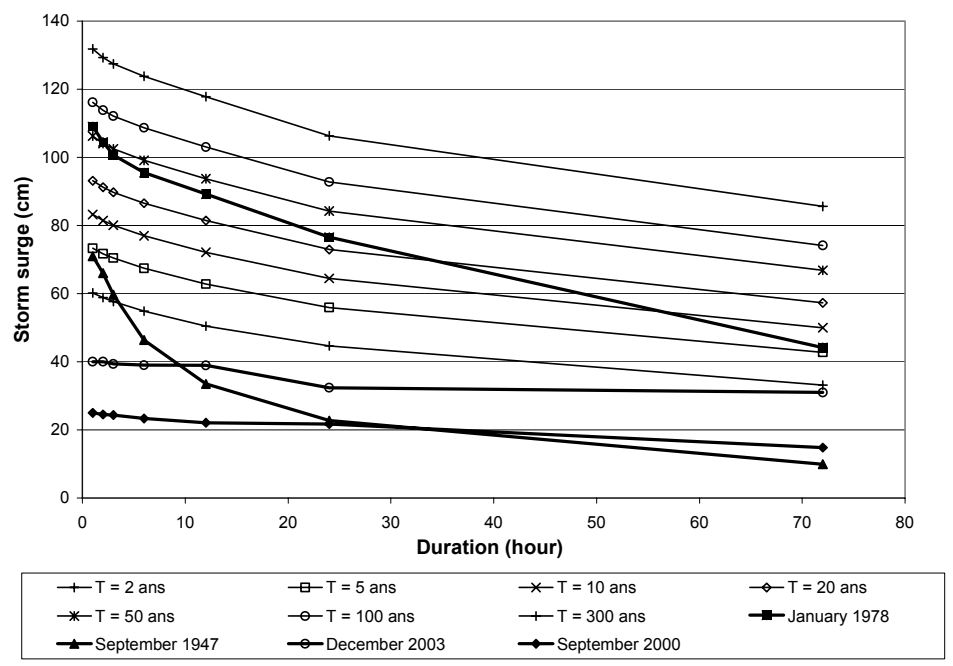

Figure 6: Storm events plotted on IDF curves.

\section{Conclusions}

Comparative analysis of several frequential models for the Marseilles (18852003) storm surge data set confirms the results obtained by Walton [6]: all the usual laws tested (MA method) are applicable for the current frequencies $(\mathrm{T}<50$ $\mathrm{yr}$ ) and $3 \mathrm{p}$ laws guarantee a better adjustment for the interval $\mathrm{T}=[50 \mathrm{yr}, 100$ $\mathrm{yr}$. Beyond, the confidence interval of $3 p$ distributions widens clearly and GEV 2 type laws are recommended here (domain of attraction of Frechet) taking into account the hyperexponential behavior of the studied series. The POT method adjustments fit best but require more care in the data processing. The major interest of this study lies in the coincidence of the statistical optimum threshold and the morphological threshold observed on the littoral of Camargue. Eventually, an original synthetic representation of storm surge including the temporal dimensions of the phenomenon is proposed. Intensity-DurationFrequency are an operational tool for analysis of the surge climate and comparison of the associated storms, for which the hydrosedimentary answers on the coast are intensity and duration dependent.

\section{Acknowledgements}

First author would like to thank G. Caude, chairman, J. L'Her and G. Grimaldi of CETMEF who authorized to publish this information, B. Simon (SHOM) and G. Wöppelmann (LAREG) for access to water level observation data, D. Fournier, G. Glaziou and B. Vion of Ministry of Transport for various contributions in the data processing. 


\section{References}

[1] Sabatier F, Suanez S., Evolution of the Rhône delta coast since the end of the $19^{\text {th }}$ century, Géomorphologie: relief, processus, environnement, 4 , pp. 283-300, 2003.

[2] Simon B., Statistique des niveaux marins extrêmes le long des cotes de France, rapport d'étude SHOM n0001/04, DPNM, Ministère de l'Equipement, 78 p., 1994.

[3] Pirazzoli P.A., Surges, atmospheric pressure and wind change and flooding probability on the Atlantic coast of France, Oceanologica Acta, 23, pp. 643-661, 2000.

[4] Bruzzi C., Les tempêtes et l'évolution morphosédimentaire des plages orientales $d u$ delta $d u$ Rhône. Thèse sci.: Univ. de Provence (AixMarseille I), 325 p., 1998.

[5] Wöppelmann G., Rattachement géodésique des marégraphes dans un système de référence mondial par techniques de géodésie spatiale. Th. Sci. Obs. Paris, 255 p., 1997.

[6] Walton T. L., Distributions for surge extremes, Ocean Ing., 27, pp. 12791293, 2000.

[7] Vella C., Provansal M., Relative sea level rise and neotectonic events during the last 6500 years on the southern eastern Rhone delta, Marine Geology, 170, pp. 27-39, 2000.

[8] Gumbel E.J., Statistics of extremes, Columbia University Press, N.Y., 375 p., 1958.

[9] Jenkinson A.F., Statistics of extremes. Estimation of maximum floods, Tech. Note No .98, World Meteorological Organization, Geneva, pp. 183$227,1969$.

[10] Mousavi N. S., Composition des lois élémentaires en hydrologie régionale: application à l'étude des régimes de crue, Thèse Univ. J. Fourier, Grenoble, 164 p., 1997.

[11] Miquel J., Guide pratique d'estimation des probabilités de crues, Ed Eyrolles, Paris, 1984.

[12] Lang M., Ouarda T., Bobée B., Towards operational guidelines for overthreshold modeling, Journal of Hydrology, 225, pp. 103-117, 1999.

[13] Pugh D.T., Vassie J.M., Applications of the Joint Probability Method for extreme sea level Computation, Proc. of the Inst. of Civil Engineers, Part 2, Vol. 69, pp. 959-975, 1980. 